\title{
As Percepções de um Professor e Alunos sobre o Ensino e as Questões de Ciências do PISA de 2015
}

\section{Teacher and Students' Perceptions of the Teaching and the Science Questions of PISA 2015}

\author{
Adriana Aparecida Ranulfo ${ }^{\circledR}$ Brasil \\ Geraldo W. Rocha Fernandes ${ }^{\circledR}$ Brasil \\ Luciana Resende Allain ${ }^{\circledR}$ Brasil
}

Esta pesquisa teve o objetivo de caracterizar as percepções de um professor e dos seus alunos sobre o ensino e as questões de Ciências do Programa Internacional de Avaliação de Estudantes (PISA) de 2015. Os dados foram coletados por meio de um grupo focal com 12 alunos que participaram da edição do PISA em 2015 e por uma entrevista semiestruturada com o professor de Ciências da escola. A partir da Análise Textual Discursiva (ATD), emergiram categorias e subcategorias para as percepções destes dois grupos de sujeitos da pesquisa. Para o professor, emergiram três categorias, a saber: 1) Percepções sobre o PISA: 2) Percepções sobre os conteúdos de Ciências; e 3) Percepções sobre a formação docente. Para o grupo de alunos, emergiram três categorias pela ATD: 1) Percepções sobre o PISA; 2) Percepções sobre os tipos de conhecimento científico; e 3) Percepções sobre o letramento científico do discente. Foi possível verificar que a prova do PISA não é valorizada nem pela escola e nem pelos estudantes, que existe uma falta de interesse dos alunos em relação aos objetivos da escola e pelas avaliações sistêmicas. Também verificou-se uma dificuldade em desenvolver a alfabetização científica, assinalando possíveis indicadores para o baixo resultado na avaliação de Ciências do PISA.

Palavras-Chave: PISA; Alfabetização Científica; Ensino de Ciências.

This research aimed to characterize the perceptions of a teacher and their students regarding the teaching and the science questions of the Programme for International Student Assessment (PISA) of 2015. Data were collected through a focus group with 12 students who participated in the PISA 2015 and a semistructured interview with the school's science teacher. From the Discursive Textual Analysis (DTA), categories emerged for these groups of participants of the study. For the teacher, three categories emerged, namely: 1) Perceptions about PISA: 2) Perceptions about contents of sciences; and 3) Perceptions about teacher education. For the group of students, three categories emerged: 1) Perceptions about PISA; 2) Perceptions about types of scientific knowledge; and 3) Perceptions of the student's scientific literacy. It was possible to verify that the PISA 
test is esteemed neither by the school nor by the students, that there is a lack of perspective of the students in relation to the school's objectives and the systemic evaluations. A difficulty was also encountered in developing scientific literacy, highlighting possible indicators for the poor outcome in the science assessment of PISA.

Keywords: PISA; Scientific Literacy; Science Education.

\section{Introdução}

O Programa Internacional de Avaliação de Estudantes, do inglês Programme for International Student Assessment (PISA), é uma avaliação internacional de larga escala, de habilidades e conhecimentos propostos aos estudantes na faixa etária dos 15 anos e 3 meses aos 16 anos e 2 meses. Esta faixa etária de idade está relacionada com o término da educação básica obrigatória na maioria dos países participantes. Assim, o PISA visa aferir até que ponto os estudantes adquiriram conhecimentos e habilidades essenciais para a participação efetiva na sociedade (Inep, 2011).

Este tipo de avaliação acontece trienalmente e abrange três áreas do conhecimento: Leitura, Matemática e Ciências. A cada edição do programa, dois terços da avaliação estão relacionados com uma área de conhecimento (Inep, 2011). Na primeira edição, no ano 2000, o foco foi em Leitura, em 2003, em Matemática e em 2006, em Ciências. Em 2009 e 2018 iniciou-se um novo ciclo do programa com ênfase em Leitura (2009 e 2018), Matemática (2012) e Ciências (2015).

Em busca de respostas sobre a qualidade do ensino de Ciências no Brasil, relatórios disponibilizados pelo INEP ${ }^{1}$ indicam que na avaliação de 2009 do PISA, em um ranking de 65 países, o Brasil foi o $53^{\circ}$ colocado em Ciências, estando muito abaixo da média (Inep, 2010). Em 2012, o Brasil ocupou o 59 lugar (Inep, 2013) e em 2015, foi o $63^{\circ}$ país em 70 países participantes (Inep, 2016c). Estes resultados nos fazem refletir sobre o que realmente esta avaliação está medindo, quais as características qualitativas da amostra que realiza a prova, e, por fim, a qualidade do ensino de Ciências no Brasil. Para Fernandes e Santos (2018), o problema estaria na política educacional, nas condições de trabalho, na carência, formação e valorização de professores. Para eles, a melhoria da qualidade do ensino de Ciências, depende, também, da adequada formação inicial, continuada e permanente dos professores da educação básica, atrelada às necessárias melhorias das condições de trabalho e salariais destes.

Segundo Carvalho (2009), nos últimos anos, o PISA tem sido considerado como um dos principais meios de ação/intervenção da Organização para a Cooperação e Desenvolvimento Econômico (OCDE) na área de educação, sendo apresentado como um estudo que objetiva responder, com regularidade, às exigências dos países membros no que tange aos conhecimentos, competências e habilidades dos seus estudantes. Portanto, o programa tem servido como instrumento para fornecer documentos que

1 Disponível em: http://portal.inep.gov.br/PISA 
divulgam dados e análises sobre o desempenho dos estudantes e dos sistemas de ensino desses países (Carvalho, 2009). O PISA também aponta indicativos sobre algumas particularidades do ensino de Ciências, ainda que pesem diferentes visões entre os pesquisadores da área sobre a pertinência deste instrumento de avaliação no contexto brasileiro. Dentre as principais críticas ao PISA como instrumento avaliativo, destacamse o distanciamento da realidade nacional; o fato de se constituir em uma avaliação amostral; o fato de ser uma avaliação por idade e não por etapas de escolarização; a comparação entre países com realidades completamente diferentes etc. Desta forma, este estudo propõe-se a distanciar das críticas sobre esta avaliação e a se aproximar das percepções de um grupo de alunos e seu professor de Ciências sobre esta avaliação.

Assim, o objetivo deste trabalho é conhecer o que pensam os professores e alunos sobre o PISA e o ensino de Ciências. Por se tratar de um estudo de caso, a pesquisa está organizada em dois objetivos específicos: 1) Identificar a percepção de um docente de Ciências sobre o PISA; 2) Identificar a percepção dos discentes que fizeram o PISA e o ensino de Ciências que tiveram na escola.

É justamente na compreensão desses aspectos que se justifica a relevância deste trabalho. Através das percepções de quem participou deste modelo de avaliação, esta pesquisa busca compreender algumas particularidades do PISA e possíveis contribuições para o ensino de Ciências. Para tanto, este estudo inicia-se com a definição do PISA como uma avaliação sistêmica, que avalia o ensino de Ciências na perspectiva do letramento científico (Inep, 2016c) em comparação à alfabetização científica (Hazen \& Trefil, 1995; Sasseron \& Carvalho, 2011; Roberts, 2007).

\section{Alguns Elementos que Caracterizam o PISA}

\section{O PISA como avaliação externa, de larga escala ou sistêmica}

As avaliações externas, de larga escala ou sistêmicas são executadas pelos Sistemas de Monitoramento de ensino municipais, estaduais, federais e internacionais e são diferentes das avaliações escolares que os professores realizam com seus alunos. Segundo Maia e Justi (2008), os objetivos das avaliações externas vinculam-se ao diagnóstico de o que os alunos aprendem nas escolas, cujos resultados devem servir para o direcionamento específico das atividades e processos de ensino desenvolvidos em sala de aula, definições de políticas públicas e organização de currículos escolares.

Em geral, esse tipo de avaliação tem como objetivo diagnosticar as possíveis insuficiências na aprendizagem de estudantes e direcionar ações pedagógicas, administrativas e financeiras contribuindo para a formulação de políticas educacionais e para o planejamento do trabalho escolar com o intuito de melhorar a qualidade da educação (Wittmann, 2008).

Neste sentido, na década de 90, foram criados no Brasil instrumentos nacionais que pudessem caracterizar a realidade do ensino da educação básica, principalmente no ensino fundamental. Entre eles, destaca-se o Sistema de Avaliação da Educação 
Básica (SAEB). No início da década de 2000 foi criado o Índice de Desenvolvimento da Educação Básica (IDEB), indicador do Ministério da Educação (MEC), elaborado pelo Instituto Nacional de Estudos e Pesquisas Educacionais "Anísio Teixeira" (INEP), que reúne os dados do SAEB e da Prova Brasil. Estas avaliações têm, por um lado, o objetivo de mensurar habilidades cognitivas dos estudantes em conteúdos pertinentes às áreas de Língua Portuguesa e Matemática, e, por outro lado, o objetivo de oferecer um indicativo sobre a possível qualidade de ensino, que é ministrado nas escolas, subsidiando, desta forma, tomadas de decisão da gestão escolar.

O SAEB e a Prova Brasil não têm o objetivo de conhecer a real qualidade do ensino de Ciências que é ofertado no ensino fundamental. Portanto, o principal indicador sobre o ensino de Ciências do Brasil ainda provém do PISA. Em 2018, o MEC anunciou que começaria a avaliar a qualidade do ensino de Ciências, a partir de 2019, por meio do SAEB, para alunos do $9^{\circ}$ ano do ensino fundamental, conforme consta na Base Nacional Comum Curricular (BNCC), aprovada no final de 2017 e homologada em 2018. Entretanto, até a presente data, tal avaliação não foi oficializada pelo MEC.

O Plano Nacional de Educação - PNE (MEC, 2014) salienta as diferenças entre o SAEB e o PISA, como, por exemplo, o fato de as duas avaliações não possuírem a mesma escala de proficiência e a ausência de itens comuns que possam ser utilizados para que as escalas sejam comparadas. Por exemplo, os alunos avaliados no PISA têm faixa etária de 15 anos, indiferente do ano que estejam cursando, enquanto o SAEB avalia alunos do $5^{\circ}$ e $9^{\circ}$ anos do Ensino Fundamental (EF) e do $3^{\circ}$ ano do Ensino Médio (EM), não considerando a idade. O SAEB mede a proficiência dos alunos em língua portuguesa e matemática, não deixando claro qual a real qualidade do ensino de Ciências e a proficiência dos alunos em relação a esta área do conhecimento no Brasil.

Em 2015, o PISA teve, no Brasil, a participação de 23.141 estudantes nascidos aproximadamente no ano de 1999, matriculados a partir do $7^{\circ}$ ano do Ensino Fundamental, distribuídos em 841 escolas (Inep, 2016a). Pela primeira vez, a aplicação da prova no Brasil foi totalmente realizada pelo computador e as informações contextuais foram coletadas por meio de três tipos de questionários: Questionário do Aluno, Questionário do Professor e Questionário da Escola. Os estudantes tiveram duas horas para responder as questões de ciências, leitura, matemática e resolução colaborativa de problemas e 35 minutos para responder os questionários.

As questões do PISA 2015 foram organizadas em dois grupos. O primeiro era formado por unidades padrão: constituídas por questões associadas com material estático que inclui textos, figuras, tabelas e gráficos e o segundo, por unidades interativas: constituídas por questões associadas com material de estímulo interativo. Os formatos de resposta das questões propostas pelos itens do PISA em 2015 foram: múltipla escolha simples; múltipla escolha complexa; e respostas construídas ou abertas.

De acordo com Pinto, Silva, e Neto (2016), existem poucas pesquisas que investigam os resultados do ensino de Ciências neste tipo de avaliação. Existem trabalhos que buscam analisar as questões de Ciências (Nora, Broietti, \& Passos, 2016; 
Nora \& Broietti, 2017; José, Angotti, \& Bastos, 2016), as percepções dos professores sobre os resultados do PISA-2015 (Rodrigues \& Cruz, 2017), os principais fatores que influenciam nos resultados do PISA, de acordo com a literatura publicada (Pinto, Silva, \& Neto, 2016). Para nós, a falta de estudos que relacionam o PISA e o ensino de Ciências está nas principais críticas que existem sobre este programa. Segundo Sjøberg (2017), sendo o PISA o principal instrumento da OCDE, os resultados deste programa têm emergido como um tipo de ministério global da educação, promovendo seus próprios currículos e sistemas de qualidade de avaliação padronizados. Para este autor, a preocupação principal dos resultados do PISA é com a economia nacional e não com o desenvolvimento pessoal do aprendiz. Sjøberg (2017) também considera que o modelo proposto pelo PISA não pode identificar relações causais por detrás do sucesso ou do fracasso dos resultados e que as consequências educacionais de tais resultados não são claras. Em muitos países, os resultados do PISA são usados para legitimar reformas controladas pelo mercado, controle sobre as ações docentes, pagamento por bons resultados para professores e diretores de escolas, destruição do sistema educacional público, privatização e introdução de testes adicionais (Sjøberg, 2017). Nesse sentido, o sucesso do PISA como um instrumento de poder pode também criar inquietação, não só nos níveis nacionais e de estados, mas também no nível local, transformando-o em um produto comercial.

Apesar das diferentes críticas, o PISA é um instrumento que oferece diagnósticos, identifica pontos de dificuldade e exemplos que merecem ser investigados. Os dados são úteis para estudar as condições de educação no Brasil e no mundo. Porém, é importante esclarecer, que neste trabalho, não se busca defender ou rejeitar o programa, mas sim analisar e refletir sobre o seu processo e resultados para melhor fundamentar as suas possibilidades e seus limites, a partir do olhar de professores de Ciências e seus estudantes.

\section{O PISA e o Ensino de Ciências numa perspectiva de Alfabetização Científica ou Letramento Científico}

Sendo o PISA um instrumento diagnóstico sobre a qualidade do ensino de vários países, verifica-se na Matriz de Avaliação de Ciências (Inep, 2015b) uma discussão sobre como avaliar o letramento científico, ou seja, a visão de um aluno letrado cientificamente para a avaliação internacional de 2015 estava na busca da resposta para a pergunta: O que é importante para os jovens saberem, valorizarem e serem capazes de fazer em situações que envolvem ciência e tecnologia? (Inep, 2015b). Neste sentido, é importante resgatar as principais discussões sobre o termo "letramento científico" e "alfabetização científica” para entender o que realmente o PISA quer avaliar.

Muito se tem debatido sobre os conceitos de alfabetização científica e letramento científico, que, além de variados sentidos, enfrentam também problemas de tradução. Normalmente, estes termos relacionam o ensino de Ciências à formação cidadã dos alunos, para sua ação e atuação em sociedade. Segundo Sasseron e Carvalho (2011), os 
autores de língua espanhola, por exemplo, costumam utilizar a expressão "Alfabetización Científica" para designar o ensino cujo objetivo seria a promoção de capacidades e competências entre os estudantes capazes de permitir-lhes a participação nos processos de decisões do dia a dia. Nas publicações em língua inglesa, o mesmo objetivo aparece sob o termo "Scientific Literacy" e, nas publicações francesas, encontra-se o uso da expressão "Alphabétisation Scientifique". No ensino de Ciências brasileiro, existe um grande debate sobre a tradução dos termos: a expressão inglesa vem sendo traduzida como "letramento científico", enquanto as expressões francesa e espanhola, também são traduzidas por "alfabetização científica" (Sasseron \& Carvalho, 2011). Devido à pluralidade semântica, na literatura nacional sobre o ensino de Ciências, existem autores que utilizam a expressão "letramento científico", pesquisadores que adotam o termo "alfabetização científica" e também aqueles que usam a expressão "Enculturação Científica" para designar o objetivo desse ensino de Ciências que almeja a formação cidadã dos estudantes para o domínio e uso dos conhecimentos científicos e seus desdobramentos nas mais diferentes esferas de sua vida (Sasseron, \& Carvalho, 2011).

Para Hazen e Trefil (1995, p. 12), a alfabetização científica é "o conhecimento necessário para entender os debates públicos sobre questões de ciência e tecnologia", envolvendo um conjunto de fatos, vocabulários, conceitos e o entendimento da história e filosofia do conhecimento científico. Sasseron e Carvalho (2011) complementam o conceito de Hazen e Trefil (1995) fundamentando a alfabetização científica em três eixos estruturantes caracterizados por: i) compreensão básica de termos, conhecimentos e conceitos científicos fundamentais; ii) compreensão da natureza da ciência e dos fatores éticos e políticos que circundam sua prática; e iii) entendimento das relações existentes entre ciência, tecnologia, sociedade e meio ambiente.

Pode-se perceber que no cerne das discussões levantadas pelos pesquisadores, que usam um termo ou outro, estão as mesmas preocupações com o ensino de Ciências, ou seja, motivos que guiam o planejamento desse ensino para que a sociedade possa aplicá-lo em questões do dia a dia.

O relatório brasileiro sobre o PISA 2015, por sua vez, faz uso do termo "Letramento em Ciências" e o define como:

O letramento científico requer, além do conhecimento de conceitos e teorias, o conhecimento sobre os procedimentos e as práticas comuns associadas à investigação científica. Um jovem letrado cientificamente está preparado para participar de discussões fundamentadas sobre questões relacionadas à Ciência, pois tem a capacidade de usar o conhecimento e a informação de maneira interativa (Inep, 2016c, p. 07).

Assim, de acordo com este documento, indivíduos que são "letrados em ciência" têm o conhecimento das principais concepções e ideias que formam a base do pensamento científico e tecnológico; de como tal conhecimento foi obtido e do grau com que este conhecimento é justificado por evidências ou explicações teóricas.

O letramento científico expresso no PISA 2015 tem como indicadores quatro categorias que incluem: competências, tipos de conhecimento científico, contextos e 
demanda cognitiva. Essas categorias são explicadas em detalhe no documento da Matriz de Referência (Inep, 2015b) e estão resumidas na Figura 1.

\begin{tabular}{|c|c|}
\hline Categorias & Caracterização \\
\hline Competências & $\begin{array}{l}\text { 1. Explicar fenômenos cientificamente: reconhecer, oferecer e avaliar } \\
\text { explicações para fenômenos naturais e tecnológicos; } \\
\text { 2. Avaliar e planejar experimentos científicos: descrever e avaliarinvestigações } \\
\text { científicas e propor meios para responder cientificamente as questões; } \\
\text { 3. Interpretar dados e evidências cientificamente: analisar e avaliar dados, } \\
\text { suposições e argumentos em representações variadas e tecer conclusões } \\
\text { científicas apropriadas ao contexto. }\end{array}$ \\
\hline $\begin{array}{l}\text { Os tipos de } \\
\text { conhecimento } \\
\text { científico }\end{array}$ & $\begin{array}{l}\text { 1. Conhecimento do conteúdo das ciências: inclui os sistemas físicos, sistemas } \\
\text { vivos e sistema Terra e espaço; } \\
\text { 2. Conhecimento procedimental: conhecimento da diversidade de métodos } \\
\text { e práticas utilizadas para o estabelecimento do conhecimento científico e dos } \\
\text { procedimentos padronizados; } \\
\text { 3. Conhecimento epistemológico: Conhecimento dos recursos essenciais } \\
\text { ao processo de construção do conhecimento da Ciência: hipóteses, teorias, } \\
\text { observações. }\end{array}$ \\
\hline Contextos & $\begin{array}{l}\text { Evidências das competências e conhecimentos em uma variedade de contextos: } \\
\text { saúde; recursos naturais; ambiente; riscos; fronteiras entre ciência e tecnologia, } \\
\text { nos níveis: pessoal, local/nacional e global. }\end{array}$ \\
\hline $\begin{array}{l}\text { Demanda } \\
\text { Cognitiva }\end{array}$ & $\begin{array}{l}\text { 1. Baixa: Realizar um procedimento de uma única etapa, por exemplo, } \\
\text { recordação de um fato, termo, princípio ou conceito ou localizar uma única } \\
\text { informação em um gráfico ou tabela. } \\
\text { 2. Média: Usar e aplicar conhecimento conceitual para descrever ou explicar } \\
\text { fenômenos; selecionar procedimentos apropriados envolvendo dois ou mais } \\
\text { passos; organizar/apresentar dados, relatórios ou utilizar conjuntos de dados } \\
\text { simples ou gráficos. } \\
\text { 3. Alta: Analisar informação ou dados complexos; resumir ou avaliar } \\
\text { evidências; justificar e argumentar a partir de várias fontes de informação; } \\
\text { desenvolver um plano ou sequência de passos para abordar um problema. }\end{array}$ \\
\hline
\end{tabular}

Figura 1. Categorias e caracterização da Matriz de Referência de letramento científico do PISA de 2015

Fonte: Adaptado de Inep (2016b).

Para Vieira (2017), o letramento científico defendido pelo PISA possui um viés neotecnicista, uma vez que visa capacitar jovens que serão, ao mesmo tempo, produtores do conhecimento científico e consumidores da informação científica, para enfrentar desafios que exigem contribuições da ciência e tecnologia a partir de uma perspectiva de resultados.

Enquanto as categorias do letramento científico do PISA 2015 buscam relacionar a concepção empírica da Natureza da Ciência, os eixos estruturantes da alfabetização 
científica de Sasseron e Carvalho (2011) estão mais próximos às concepções epistemológicas e concepções sociais e culturais da Natureza da Ciência (Fernandes; Rodrigues, \& Ferreira, 2018).

Roberts (2007) destaca a inexistência de consenso na comunidade internacional de educação científica quanto à definição do termo scientific literacy. Este autor argumenta que o termo possui duas visões em lugar de definições, por entender que a visão é uma categoria analítica mais ampla. Com isso, denomina de Visão I aquele letramento que se restringe à perspectiva interna da ciência, voltada para o conteúdo científico, que para nós se aproxima das categorias e das três competências para o letramento científico expressos pelo PISA (Figura 1), e de Visão II aquele em que os estudantes se veem como cidadãos e percebem que os conteúdos científicos podem ajudar na compreensão de conhecimentos fundamentais da Ciência; na compreensão da natureza da Ciência; dos fatores éticos e políticos envolvidos na sua dimensão prática e do entendimento das relações existentes entre ciência, tecnologia, sociedade e meio ambiente, isto é, se aproximam mais dos eixos estruturantes da alfabetização científica de Sasseron e Carvalho (2011).

A partir do exposto anteriormente, passamos a contemplar os objetivos iniciais deste trabalho, ou seja, identificar a percepção dos docentes de Ciências e discentes sobre o PISA e o ensino de Ciências vivenciado por eles, numa perspectiva de "alfabetização científica" ou "letramento científico".

\section{Metodologia}

\section{Caracterização da Pesquisa}

A presente pesquisa tem uma abordagem qualitativa (Lüdke \& André, 1986) e também se caracteriza como um estudo de caso, uma vez que tem o objetivo de explorar, descrever, explicar, avaliar e/ou transformar um determinado contexto específico (Sousa, 2009). Trata-se de um estudo de caso, uma vez que esta pesquisa busca compreender as percepções de um grupo de estudantes e de seu professor sobre o PISA e o ensino de Ciências de uma escola pública, "considerados como entidade única, diferente de qualquer outra, numa dada situação contextual específica, que é o seu ambiente natural" (Sousa, 2009, p. 138).

A coleta de dados desta pesquisa foi desenvolvida em uma escola pública do município de Congonhas do Norte, localizada no Vale do Jequitihonha, no estado de Minas Gerais e contou com 12 alunos que participaram da edição do PISA em 2015 e seu professor de Ciências. A escolha da escola para esta pesquisa deve-se ao fato de a mesma ter sido a única escola do Vale do Jequtinhonha a participar do PISA em 2015. Já a amostra dos alunos participantes foi formada pelo aceite de 12 dos 20 estudantes que ainda estavam presentes na escola, uma vez que vários haviam saído da escola depois de 2015. Neste trabalho não serão apresentados o nome da escola e dos sujeitos participantes de modo a preservar a identidade dos pesquisados. 
Para conhecer o que pensam os professores e alunos sobre o PISA e o ensino de Ciências, a coleta de dados com o professor de Ciências foi realizada através de uma entrevista semiestruturada (Lüdke \& André, 1986) que durou aproximadamente 30 minutos. Os pesquisadores buscaram seguir um roteiro com questões previamente definidas sobre o PISA e o ensino de Ciências em um contexto muito semelhante ao de uma conversa informal (Lüdke \& André, 1986). O roteiro foi dividido em dois eixos. O primeiro era composto por questões que buscavam compreender as percepções do professor sobre o PISA, por exemplo:

1. Qual a sua opinião sobre o PISA?

2. Qual a sua avaliação de uma prova sistêmica de Ciências ser aplicada pelo computador?

3. Você percebeu se os alunos tiveram interesse? E dificuldade?

4. O que você achou das questões de ensino de Ciências da prova do PISA?

Já o segundo eixo era composto por questões que buscavam compreender a percepção do professor sobre o ensino de Ciências desenvolvido na escola, por exemplo:

1. Você desenvolve atividades de Ciências? Como?

2. Os seus alunos apresentam algum interesse em investigarem questões científicas?

3. Você percebe se os alunos conseguem fazer a associação dos conteúdos de Ciências ensinados com questões do dia a dia?

4. Em atividades de trabalho em grupos, os alunos conseguem interagir uns com os outros?

5. Você percebe se seus alunos conseguem utilizar conhecimentos científicos em problemas sociais?

6. Os alunos apresentam interesse e curiosidade nas aulas de Ciências?

Para a coleta de dados com os discentes, foi realizado um Grupo Focal (GF) em que participaram 12 alunos com duração de 50 minutos. Segundo Gui (2003), o grupo focal é uma forma de entrevista em grupo, baseada na comunicação e na interação. Seu principal objetivo é reunir informações detalhadas sobre um tópico específico sugerido por um pesquisador, coordenador ou moderador do grupo, a partir de um grupo de participantes selecionados. Ele busca colher informações que possam proporcionar a compreensão de percepções, crenças, atitudes sobre um tema, produto ou serviços. Para nós, o GF consistiu na busca das percepções dos alunos sobre o ensino e as questões de Ciências do PISA 2015. Na época da realização do PISA, o grupo participante estava no $9^{\circ}$ ano do EF. Para os discentes, o roteiro do grupo focal também foi organizado em dois eixos: compreensão da percepção dos discentes sobre o PISA e sobre o ensino de Ciências. No primeiro eixo havia questões com o objetivo de gerar reflexões e um debate sobre:

1. A experiência de fazer uma prova pelo computador;

2. A caracterização das questões da prova do PISA; e

3. A demanda cognitiva das questões.

O segundo eixo, buscou respostas sobre a qualidade do ensino e a sua relação 
com a alfabetização científica, por exemplo:

1. Caracterização do ensino de Ciências;

2. A capacidade de explicar fenômenos científicos;

3. A capacidade de avaliar e planejar experimentos científicos; e

4. A capacidade de interpretar dados e evidências científicas.

Foi fornecido aos alunos um "Termo de Consentimento Livre e Esclarecido", explicando os objetivos da pesquisa. As falas dos entrevistados foram gravadas e transcritas na íntegra. $\mathrm{Na}$ apresentação dos resultados, os alunos participantes serão denominados de A1, A2, A3 etc.

Para a análise da entrevista e do grupo focal foi utilizada a Análise Textual Discursiva (ATD) de Moraes e Galiazzi (2011). A ATD se caracteriza como “(...) uma abordagem de análise de dados que transita entre duas formas consagradas de análise de pesquisa qualitativa, que são a análise de conteúdo e análise de discurso (Moraes \& Galiazzi 2011, p. 118)”. De acordo com Moraes e Galiazzi (2011), os dados foram "recortados, pulverizados, desconstruídos, sempre a partir das capacidades interpretativas do pesquisador" (p. 132).

Segundo Moraes e Galiazzi (2011), o processo da ATD é realizado em três etapas:

a) Unitarização: os textos analisados, ou seja, as falas dos participantes foram separadas por seus significados. É importante destacar que esta separação pode, ainda, gerar outras unidades teóricas e empíricas por parte do pesquisador que poderá utilizar suas próprias palavras para melhor compreensão do texto. Nessa pesquisa, foi realizada a fragmentação das falas dos alunos e do professor de Ciências.

b) Categorização: nesse momento, os dados são separados por unidades de significado, ou seja, por semelhança de significados. Nessa pesquisa, foi o momento em que se organizou as unidades de significados das respostas dos participantes em categorias e subcategorias “emergentes”. Em relação às percepções do docente, emergiram três categorias de análise: 1) Percepções do docente sobre o PISA; 2) Percepções do docente sobre o conhecimento dos conteúdos de Ciências; 3) Percepções do docente sobre formação docente. Para as percepções dos alunos, as categorias que emergiram foram: 1) Percepções dos discentes sobre o PISA; 2) Percepções dos discentes sobre os tipos de conhecimento científico; 3) Percepções sobre o letramento científico do discente.

c) Metatexto: trata-se de textos descritivos e interpretativos que analisam as categorias relevantes da pesquisa. Segundo Moraes (2003),

[...] os metatextos são constituídos de descrição e interpretação, representando o conjunto, um modo de compreensão e teorização dos fenômenos investigados. A qualidade dos textos resultantes das análises não depende apenas de sua validade $\mathrm{e}$ confiabilidade, mas é, também, consequência do pesquisador assumir-se como autor de seus argumentos (p. 202).

Nessa fase, o pesquisador se esforça em expressar suas intuições e novos entendimentos a partir da sua rigorosa e ostensiva análise dos dados. A validade e 
confiabilidade dos resultados de uma análise, segundo Moraes (2003), dependem "do rigor com que cada etapa da análise foi construída (p. 206)", uma vez que "uma unitarização e uma categorização rigorosas encaminham para metatextos válidos e representativos dos fenômenos investigados (p. 206)". A validade e confiabilidade da análise dos resultados desta pesquisa foram construídas ao longo do processo da ATD.

A partir dessas considerações, foram elaborados metatextos a partir de análises e interpretações dos resultados em forma de categorias e subcategorias, organizadas em dois eixos: a) Percepções do Docente (Figura 2); e b) Percepções do Discente (Figura 3).

\begin{tabular}{|l|l|}
\hline Categorias & Subcategorias \\
\hline $\begin{array}{l}\text { 1. Percepções do docente sobre } \\
\text { o PISA }\end{array}$ & $\begin{array}{l}\text { a) Concepções do professor sobre as questões de Ciências do PISA } \\
\text { b) Algumas críticas em relação ao PISA } \\
\text { c) Motivação dos alunos em fazer uma avaliação sistêmica }\end{array}$ \\
\hline $\begin{array}{l}\text { 2. Percepções do docente sobre } \\
\text { os tipos de conhecimentos } \\
\text { científicos }\end{array}$ & $\begin{array}{l}\text { a) Conhecimento dos conteúdos conceituais de Ciências } \\
\text { b) Conhecimento dos conteúdos procedimentais } \\
\text { c) Conhecimento dos conteúdos atitudinais }\end{array}$ \\
\hline $\begin{array}{l}\text { 3. Percepções do docente sobre } \\
\text { a formação docente }\end{array}$ & a) Caracterização da formação do professor de Ciências \\
\hline
\end{tabular}

Figura 2. Percepções do Docente

\begin{tabular}{|l|l|}
\hline Categorias & Subcategorias \\
\hline $\begin{array}{l}\text { 1. Percepções do discente } \\
\text { sobre o PISA }\end{array}$ & $\begin{array}{l}\text { a) Uso dos recursos tecnológicos e a resolução das questões de Ciências } \\
\text { do PISA } \\
\text { b) Demanda cognitiva em relação às questões de Ciências do PISA }\end{array}$ \\
\hline $\begin{array}{l}\text { 2. Percepções do discente } \\
\text { sobre os tipos de } \\
\text { conhecimento científico }\end{array}$ & $\begin{array}{l}\text { a) Caracterização do conhecimento do conteúdo de Ciências } \\
\text { b) Caracterização dos conhecimentos Procedimentais } \\
\text { c) Caracterização dos conhecimentos Epistemológicos }\end{array}$ \\
\hline $\begin{array}{l}\text { 3. Percepções sobre o } \\
\text { letramento científico do } \\
\text { discente }\end{array}$ & $\begin{array}{l}\text { a) Caracterização das competências requeridas para o letramento } \\
\text { científico do aluno }\end{array}$ \\
\hline
\end{tabular}

Figura 3. Percepções do Discente

\section{Resultados e Discussão}

\section{Percepções do Docente}

\section{Categoria 1: Percepções do docente sobre o PISA}

Nesta primeira categoria, foi evidenciada a percepção do professor de Ciências sobre o PISA, cujos indicadores puderam ser resumidos em: questões de Ciências, critícas ao PISA, o papel das avaliações sistêmicas e uso de recursos tecnológicos para a 
realização da prova.

a) Concepções do professor sobre as questões de Ciências do PISA

Como escrito anteriormente, o PISA, de acordo com o Inep (2016a), tem o objetivo de avaliar o índice de conhecimento científico do aluno ao longo do ensino fundamental. Para o professor, a prova apresenta questões que fazem com que os alunos usem o conhecimento científico escolar em problemas do dia a dia, a partir da associação de diferentes conteúdos: "Eles colocam na questão a resolução de situaçõesproblemas, onde isso expande o ponto de vista do aluno, aumentando a análise crítica para apresentar possíveis soluções."(Professor, grifo nosso)

O professor apresenta nesta resposta, uma visão que se aproxima das três competências científicas para o letramento científico (Inep, 2016b), uma vez que ele entende que as questões apresentam “(...) resolução de situações-problemas, (...) aumentando a análise crítica para apresentar possíveis soluções", ou seja, "o letramento científico requer, além do conhecimento de conceitos e teorias, o conhecimento sobre os procedimentos e as práticas comuns associadas à investigação científica (Inep, 2016c). Independentemente de qualquer avaliação sistêmica, Sasseron e Carvalho (2011) argumentam que é importante que o ensino de Ciências também possa desenvolver habilidades nos alunos com esse caráter investigativo, ou seja, de apresentar soluções para problemas locais, mundiais e nacionais. Nesta subcategoria, não está claro se realmente as questões do PISA conseguem avaliar esta habilidade dos alunos, ou até mesmo se o ensino de Ciências que os alunos participantes vivenciam está desenvolvendo habilidades de "resoluções de situações problemas", como descrito pelo professor.

O professor também indica que a avaliação associa diferentes conteúdos já estudados nas aulas de Ciências, além de outros conhecimentos, para resolver as questões: "Acredito que o nosso aluno teria dificuldade pelo fato de ter que associar mais de um conhecimento na resolução da questão". (Professor)

O professor tende a demostrar que o "seu" aluno não seria capaz de resolver as questões apresentadas, dando a entender que o ensino de Ciências na escola não é suficiente para que o aluno consiga "associar mais de um conhecimento na resolução da questão". Uma possibilidade para esta dificuldade do aluno estaria na forma descontextualizada do conteúdo com o seu dia a dia. Essa observação do professor não caracteriza a dificuldade dos alunos em resolver somente as questões do PISA, mas também outras avaliações sistêmicas e de aprendizagem: "o nosso aluno teria dificuldade".

b) Algumas críticas em relação ao PISA

Durante a análise das falas do professor, surgiram algumas críticas em relação ao PISA. A primeira foi a concepção negativa da escola em relação ao PISA e que está exemplificada em dois fragmentos que se seguem: “Aqui na escola, houve um tratamento do PISA com certo descaso, onde nós fomos proibidos de trabalhar... Queria levar [questões] para discutir com os alunos, aí falaram que não era para fazer...” (Professor)

O Brasil, por exemplo, é um país extremamente consumista... O que é produzido lá fora pode lançar no Brasil que vai ser consumido, comercializado e absorvido. Então, a 
partir desse ponto de vista é que nós abordamos o PISA. Nós tivemos uma reunião para discutir sobre o PISA e não foi aprofundado nenhum outro detalhe. (Professor)

O primeiro fragmento demonstra o não envolvimento da escola com a avaliação do PISA, ainda que o professor “queria levar [questões] para discutir com os alunos”. Este "descaso" da escola pode indicar duas visões iniciais em relação ao PISA. A primeira tende a ser uma visão pragmática ou desinteressada da escola em participar do programa e a segunda poderia ser uma visão mais filosófica, de que o PISA busca legitimar reformas orientadas pelo mercado, controle de professores, erosão do sistema escolar público, privatização e introdução de mais regimes de testes (Sjøberg, 2007).

O segundo fragmento de fala demostra que a escola enxerga o PISA como um produto de mercado. Como descrito, esse pensamento também é defendido por Sjøberg (2007), uma vez que o projeto PISA, organizado pela OCDE, pode ser visto como parte de uma tendência atual da política internacional, em que conceitos e ideias do mercado são usados no setor de educação.

Uma segunda crítica em relação ao PISA, refere-se à seleção dos participantes por idade e não por etapas de formação como acontece no SAEB.

O critério de seleção foi a idade [dos alunos], independentemente do rendimento satisfatório ou não. Desse fator, idade, é que os alunos foram selecionados, e dos selecionados, têm alguns aqui que evadiram logo após. (Professor)

Esta crítica do professor, relacionada ao estabelecimento de um corte na amostra por idade (entre 15 anos e 3 meses e 16 anos e 2 meses), é válida, uma vez que os sistemas educacionais não são uniformes no mundo. Nessa faixa etária, os jovens, na maioria dos países da OCDE, estão se aproximando do final do ensino obrigatório. No Brasil, a maioria dos alunos ainda estão finalizando o EF e iniciando o EM, tendo mais dois anos pela frente ( $2^{\circ}$ e $3^{\circ}$ anos do EM). Também há o problema da distorção idade-ano escolar, que costuma atingir mais fortemente os alunos das nações subdesenvolvidas. No Brasil, por exemplo, $10,2 \%$ dos estudantes que fizeram o exame estavam no $7^{\circ}$ ou $8^{\circ}$ ano, índice bem superior à média mundial $(5,9 \%)$. A variação entre os estados também é grande: enquanto em São Paulo apenas $0,4 \%$ da amostra ainda estava no $7^{\circ}$ ano, em Sergipe o número salta para $12 \%$. Desta forma, não seria adequado comparar os resultados do Brasil com os países desenvolvidos da OCDE (Inep, 2016a).

Enfim, nesta segunda subcategoria, conclui-se que o PISA gera desconfiança nas escolas onde é aplicado e pode estar medindo "tipos de conhecimentos científicos" diferentes no momento da prova (Figura 2), uma vez que a amostra de participantes no Brasil apresenta uma distorção entre a idade e o ano escolar em comparação com os países desenvolvidos da OCDE.

c) Motivação dos alunos em fazer uma avaliação sistêmica

A motivação, segundo o PISA, pode ser considerada uma força motriz por trás do interesse, do engajamento e da aprendizagem em todas as áreas do conhecimento. Para nutrir o envolvimento dos estudantes no ensino de Ciências, os sistemas escolares precisam garantir que eles tenham não só o conhecimento básico para se envolver com 
questões científicas complexas, mas também o interesse e a motivação que os levem a querer fazê-lo (Inep, 2016c). Segundo o professor, a motivação dos alunos participantes não esteve relacionada ao "interesse, engajamento e aprendizagem de Ciências", mas: "Boa parte [dos alunos] quis fazer a prova por curiosidade, já que ficaram sabendo que é uma avaliação a nível internacional: 'vou fazer algo para o mundo inteiro.' (Professor)

Verifica-se que a motivação dos participantes em fazer a avaliação do PISA não esteve relacionada com a possibilidade de verificar a aprendizagem de Ciências, mas com a curiosidade sobre a avaliação ser internacional: "vou fazer algo para o mundo inteiro".

Pela fala do professor, não está claro se a prova consegue/conseguiu verificar o interesse pela ciência, ainda que esta dimensão tivesse como um dos construtos o uso das tecnologias digitais pelos participantes. O que se pode perceber é um grande desinteresse dos alunos pelas avaliações sistêmicas, conforme se observa neste trecho da entrevista com o professor:

Infelizmente, de modo geral, os nossos alunos tratam as avaliações com descaso muito grande, tanto as questões das avaliações do sistema mineiro, o SIMAVE, tanto as outras, como a Prova Brasil. Eles pegam o papel, as provas internas bimestrais, e marcam de qualquer forma para terminar. Eles querem cumprir o papel de fazer a avaliação e não em se dedicar na questão da realização de uma avaliação de qualidade, quer simplesmente fazer. [...] Aqui, a gente vem coletando resultados bem negativos [...]. O aluno recebe o pacote de prova e quando a gente termina de entregar [para todos], ele já coloriu o gabarito sem antes abrir o caderno de prova, mas, como o PISA é uma prova que não é feita no papel, mas em um sistema informatizado, ele não teve essa opção, teve que tentar dedicar um pouco mais. (Professor)

Percebe-se nesta fala que o resultado de Ciências também é influenciado pela falta de interesse do aluno em fazer a avaliação: "Eles pegam o papel, as provas internas bimestrais, e marcam de qualquer forma para terminar". Neste sentido, parece haver uma tendência entre os alunos, independentemente do tipo de avaliação (sistêmica ou escolar), em não compreender o real objetivo de serem avaliados, dificultando a avaliação da aprendizagem, o que tende a contribuir para um baixo resultado nos exames.

Trabalhos recentes indicam que o fraco desempenho dos alunos brasileiros no PISA não ocorre apenas porque eles não acertam as perguntas da prova. A maioria dos estudantes não sabe o que é solicitado, tem dificuldade de entender os enunciados e não consegue chegar ao fim da prova (Saldanha, 2018). Pode-se pensar que estes indicadores tenham uma relação com a falta de estímulo da escola (primeira subcategoria) e que esta pode influenciar na motivação dos alunos participantes desta pesquisa em fazer a prova e, consequentemente, nos seus resultados.

Como conclusão, percebe-se que os alunos não demonstraram motivação em fazer a avaliação do PISA, somente curiosidade em conhecê-la, especialmente por ser internacional e informatizada. 


\section{Categoria 2: Percepções do docente sobre os tipos de conhecimento científico}

A segunda categoria refere-se à visão do professor sobre os conhecimentos que são desenvolvidos nas aulas de Ciências e a relação com o letramento científico proposto pela avaliação do PISA. A partir da visão do professor, foi possível verificar que os conhecimentos desenvolvidos nas suas aulas de Ciências podem ser organizados, de acordo com Coll (2000), em conhecimentos e conteúdos conceituais, procedimentais e atitudinais.

\section{a) Conhecimento dos conteúdos conceituais de Ciências}

Para efeitos da avaliação do PISA, as competências necessárias para o letramento científico (explicar fenômenos cientificamente, avaliar e planejar investigações científicas e interpretar dados e evidências cientificamente) são testadas usando o conhecimento que se pode esperar dos estudantes de 15 anos. Coll (2000) chama a atenção que a competência em construir novos conhecimentos envolve a mobilização de diferentes conteúdos, atrelados aos aspectos pessoais e à capacidade de se relacionar com o outro. Assim, na avaliação do PISA, o conhecimento do conteúdo científico foi selecionado com base nos principais campos da Física, Química, Biologia e Ciências.

No fragmento de fala "A gente está buscando essa associação de atrelar esses conceitos técnico-científicos na vida prática deles." (Professor, grifo nosso), o professor entende que o ensino de conteúdos conceituais deva estar associado com questões do dia a dia dos alunos. Nesta mesma direção, existem autores que defendem esta aproximação (Delizoicov, Angotti, \& Pernambuco, 2011; Fernandes et al., 2018), uma vez que também entendem que o letramento científico requer não apenas o conhecimento de conceitos e teorias da ciência, mas também o conhecimento sobre procedimentos e práticas associadas à investigação científica e ao avanço da ciência.

A reflexão do professor sobre os entendimentos acerca da "aplicação dos conceitos técnico-científicos na vida prática" dos alunos não responde à complexidade do ensino de Ciências. Outros questionamentos poderiam surgir, por exemplo: de que conceitos os alunos precisam e para quais práticas eles os necessitam? Acreditamos que, para a compreensão destes questionamentos, é necessário abordar conteúdos e conceitos numa perspectiva de alfabetização científica, como proposto por Sasseron e Carvalho (2011), de forma crítica, ampliada e que articule teoria e prática. Assim, a partir da compreensão do contexto histórico-social, pode ser possível que os alunos articulem o seu novo conhecimento às situações práticas do seu dia a dia.

b) Conhecimento dos conteúdos procedimentais

Durante a análise das falas do professor, verificou-se também a presença dos conteúdos procedimentais nas aulas de Ciências que, para ele, se restringem ao desenvolvimento de atividades experimentais. As aulas expositivas, aliadas às aulas práticas no ensino de Ciências, são importantes por desenvolver no aluno competências e habilidades cognitivas que auxiliam na assimilação dos conteúdos científicos abordados. Em relação ao ensino de Ciências, o professor argumenta que ele conseguia desenvolver atividades práticas com os seus alunos: "No espaço que tinha destinado, eu 
conseguia trabalhar o laboratório, mas a partir daí, a demanda aumentou e o laboratório foi desativado e virou sala de aula". (Professor)

Uma das grandes vantagens das atividades experimentais é a possibilidade de, através delas, discutir: a relação e a presença da ciência e da tecnologia no dia a dia dos alunos; as relações sociais associadas à produção do conhecimento científico; as implicações ambientais, decorrentes da atividade científica, entre os conceitos científicos em destaque e o cotidiano dos alunos (Gonçalves \& Marques, 2006). Mesmo que tenham sido evidenciados alguns conteúdos procedimentais na fala do professor ("eu conseguia trabalhar o laboratório"), é importante destacar que somente o desenvolvimento de atividades experimentais e o uso do laboratório não garantem que o estudante seja alfabetizado cientificamente. É preciso que tais conteúdos incluam também procedimentos que requeiram dos estudantes: um trabalho de investigação; uso de técnicas gerais de estudo; estratégias que possibilitam e facilitam a comunicação; o estabelecimento de relações entre os conceitos; destrezas manuais com equipamentos concretos e virtuais, entre outros (Hazen \& Trefil, 1995; Sasseron \& Carvalho, 2011). Deste modo, não está claro se tais habilidades são desenvolvidas em suas aulas e como elas ajudaram os seus estudantes a responderem as questões do PISA.

Em outro fragmento, o professor indica que os alunos que participaram do PISA apresentam dificuldades em caracterizar, demonstrar e aplicar o processo investigativo.

[...] na hora de detalhar o processo, aí aparece o problema! Então, eles têm dificuldade de falar e explicar o processo, de aplicar e de demonstrar. Por exemplo, fazer uma demonstração, de por exemplos matemáticos na teoria e na contextualização do processo, eles até conseguem expressar com o linguajar deles, mas quando têm que associar e explicar, aí eles têm dificuldades. (Professor)

Para Gonçalves e Marques (2006), uma atividade investigativa não pode se reduzir a uma mera observação ou manipulação de dados - ela deve levar o aluno a refletir, a discutir, a explicar e a relatar seu trabalho aos colegas. Neste sentido, independentemente de qualquer avaliação sistêmica, é importante que o ensino de Ciências desenvolva habilidades nos alunos com esse caráter investigativo, ou seja, de apresentar soluções para problemas em diversas escalas. Nesta subcategoria, o que não está claro é se realmente as questões do PISA conseguem avaliar esta habilidade dos alunos, ou até mesmo se o ensino de Ciências que os alunos participantes vivenciam está desenvolvendo habilidades de "associar e explicar", como mencionado pelo professor.

c) Conhecimento dos conteúdos atitudinais

Um dos objetivos do ensino de Ciências é desenvolver atitudes que levem os estudantes a se envolver com questões científicas. Os conteúdos atitudinais apontam para uma necessidade de os alunos vivenciá-los de modo concreto nas escolas, buscando a construção de valores e atitudes (Coll, 2000). Desta forma, foi possível perceber na fala do professor a importância do trabalho em grupo para o desenvolvimento de competências atitudinais, o que está coerente com a Matriz de Avaliação de Ciências do PISA (Inep, 2015b): "[Os alunos] conseguiam desenvolver esses trabalhos quando 
formavam os grupos, aí eles correspondiam.” (Professor)

Falar das atitudes que se esperam dos alunos em sala de aula ("quando formavam os grupos") remete, em geral, aos comportamentos que favorecem o aprendizado de conteúdos conceituais e procedimentais ([os alunos] conseguiam desenvolver esses trabalhos). A nosso ver, esta constatação do professor está de acordo com Lebrun (2008, p. 164), ao afirmar que "os trabalhos de grupo são importantes para desenvolver as competências relacionais e sociais dos estudantes, mas igualmente no plano cognitivo (compreensão, análise, avaliação...)". Nesta interação promovida pelo trabalho em grupo, "o estudante será levado a explicitar, a aprofundar, confrontar, argumentar, avaliar, transformar os seus conhecimentos, em suma, a executar as alterações conceituais" (Lebrun, 2008, p. 164) e também as atitudinais.

É importante destacar que os conteúdos atitudinais não se referem somenteà atitude esperada para o trabalho em grupo e a busca de seu êxito ("aí eles correspondiam"), mas, também, aos sentimentos ou aos valores que os alunos atribuem a determinados fatos, normas, regras, comportamentos ou atitudes. Neste sentido, os conteúdos atitudinais também estão relacionados ao que se espera de um aluno dentro e fora da escola. $\mathrm{O}$ fragmento de fala do professor caracteriza a sua percepção em relação às atitudes dos alunos em relação à escola:

Sinto que o aluno não vê a escola como algo para o crescimento, simplesmente passa pela escola. Percebo que os alunos de hoje não têm o interesse de utilizar a escola como sendo uma porta de acesso a alguma melhoria da qualidade de vida, de conseguir um emprego melhor, uma formação... Toda essa questão, que necessita desta multidisciplinariedade, causa impacto nos alunos de forma negativa, porque tratam com descaso [a escola] e isso, de não conseguir associar a outra matéria, pode ter problema. (Professor - grifo nosso)

Percebe-se, neste último fragmento de fala, que uma das possíveis causas para o resultado negativo do Brasil no PISA é a falta de visão do aluno sobre o papel da escola. O professor diz: “[ele] simplesmente passa pela escola”. No entanto, se o aluno está se distanciando da escola, talvez seja necessário descobrir quais são as causas e/ou os motivos que contribuem para o seu distanciamento e a compreensão do seu papel como estudante. Deste modo, quais seriam os fatores (internos ou externos) que levariam os jovens a se distanciar ou se aproximar daquilo que a escola quer ensinar? Para o professor, um dos motivos é a dificuldade de associar o conteúdo com o dia a dia e de oferecer um ensino mais contextualizado com a realidade do aluno. Estas, muito provavelmente, não são as únicas explicações. É necessário um olhar para o aluno, professor e escola, como sujeitos e espaços que interagem ente si, e a partir desse olhar, buscar respostas sobre aspectos pedagógicos e socioculturais que interferem na educação. Assim, é importante levantar alguns questionamentos quanto ao sujeito "aluno": para que serve a prova do PISA? Ela vai melhorar a sua vida? O aluno tem perspectiva de futuro se concluir bem os estudos? A fala do professor é uma questão que interessa a todos em qualquer contexto social. Como está a juventude hoje, diante do que está acontecendo no Brasil, com o 
atual descrédito nas instituições e alto índice de desemprego? Diferentes variáveis podem influenciar a possibilidade de entusiasmo e motivação dos alunos diante da escola, do processo de aprendizagem e da avaliação do PISA.

\section{Categoria 3: Percepções do docente sobre a formação docente}

Nesta categoria emergiu uma subcategoria relacionada à formação do professor de Ciências. Segundo o Inep (2016a), a carreira de professor deve ser pensada como um processo de aprendizagem constante, e não somente como a oferta de uma formação inicial. De fato, os países de melhor desempenho no PISA empenham-se em não só oferecer formação de qualidade aos professores iniciantes, mas também oportunidades e incentivos para o desenvolvimento profissional contínuo ao longo da sua carreira.

a) Caracterização da formação do professor de Ciências

Sabe-se que a formação do educador não é um processo pontual, mas um processo que deve ser realizado continuamente ao longo de sua trajetória profissional, acompanhando as mudanças na sociedade, os avanços científicos e tecnológicos etc. Segundo o professor participante, uma possibilidade para a melhoria do ensino de Ciências e, consequentemente para a melhoria da aprendizagem dos alunos, estaria na formação continuada do professor: "A escola poderia proporcionar a esses professores um programa interno de formação continuada, o que seria interessante. Não é fácil fazer, mas seria interessante!" (Professor)

Segundo Fernandes e Santos (2018), alguns cursos de formação inicial e continuada têm deixado a desejar em relação à contextualização do ensino e à valorização de experiências e práticas vivenciadas pelos professores, pois não basta oferecer uma formação instrumental, isto é, discutir os recursos técnico-pedagógicos que a profissão exige, mas, de acordo com Maia e Justi (2008), há de se insistir na intenção de tornar o professor sujeito nas transformações sociais e educacionais.

Outros estudos, como o de Gatti (2009), apontam que a formação de professores de Ciências no Brasil sempre foi feita de forma fragmentada entre componentes disciplinares (Química, Física, Biologia e Geociências) e entre níveis de ensino, muito diferente da formação de professores que é oferecida em outros países que também participam do PISA. Para a autora, os cursos de licenciatura deveriam reservar maior carga horária para a formação para a docência, pois apesar de ser importante, não basta conhecer e dominar os conteúdos específicos. Porém, esta fragmentação por componentes e por conteúdos não foi evidenciada na nossa pesquisa como uma dificuldade para a realização das questões do PISA pelos alunos.

Eu tive uma formação presencial durante quatro anos, e hoje temos uma flexibilidade. Existe um grande número de modalidade de ensino que a pessoa não necessita nem ir ao polo para que ela tenha esse auxílio na formação, então, assim se forma. É interessante essa flexibilidade de ensino chegar aonde não ia antes, mas ela se tornou muito banal. (Professor)

Verifica-se no fragmento de fala anterior, que na avaliação do entrevistado, a 
formação do professor de Ciências "se tornou banal" devido às diferentes modalidades de formação. Fernandes e Santos (2018) chamam aspectos como este de "obstáculos no ensino de Ciências". Para estes autores, existem obstáculos na formação inicial e continuada dos professores de Ciências a partir do momento em que faltam especialistas em ensino de Ciências nos cursos de formação de professores. Outro "obstáculo no ensino de Ciências" está na intensificação da oferta sucateada de formação em massa dos cursos de Licenciatura em Ciências na modalidade a distância e na falta de melhores condições de trabalho e de salário para os professores da educação básica (Fernandes \& Santos, 2018). Assim, para superar estes obstáculos é fundamental que, na formação inicial e continuada de professores, possam ser discutidas estratégias de acordo com a realidade da escola e dos alunos. Afinal, as dificuldades e problemas no espaço escolar não estão somente na formação de professores. Não se deve esquecer que, dentro da escola, as condições de trabalho, o clima institucional, a atuação dos gestores escolares, as formas de organização do trabalho, os recursos materiais e humanos, a participação dos pais e as políticas educativas também são essenciais para o desenvolvimento da educação (André, 2011). Assim, não se pode atribuir unicamente aos professores o fracasso ou o sucesso da educação (ou do ensino de Ciências), a partir de uma avaliação sistêmica. Recuperando Afonso (2009), a prestação de contas da escola sobre o aprendizado dos alunos assentase em um modelo de accountability ${ }^{2}$, que muitas vezes culpabiliza fortemente os professores pelo fracasso escolar. Esse modelo apresenta um viés incompleto, que reduz a complexidade da escola e dos desafios educacionais brasileiros.

\section{Percepções dos Discentes}

Neste eixo, que se refere aos discentes, serão analisadas três categorias emergentes: percepções dos discentes sobre o PISA e os tipos de conhecimento científico e percepções sobre o letramento científico dos discentes.

\section{Categoria 1: Percepções dos discentes sobre o PISA}

As avaliações sistêmicas, como o PISA, além de tentar identificar o que os alunos são capazes de reproduzir, em termos de conhecimento, também buscam mensurar o que eles têm apreendido em sala de aula e como aplicam o conhecimento aprendido em situações não familiares, tanto no contexto escolar quanto não escolar (Inep, 2016a). Essa perspectiva de avaliação reflete a tentativa de compreender não somente o que os alunos sabem, mas o que eles podem fazer com o que sabem, o que, muitas vezes, não está claro se realmente o conseguem. Em busca de respostas para esta categoria, emergiram na fala dos estudantes que participaram do grupo focal duas subcategorias,

2 De acordo com Afonso (2009), accountability é um conceito que relaciona três dimensões autônomas, mas fortemente articuladas: a avaliação, a prestação de contas e a responsabilização. Para ele, a introdução da avaliação estandardizada, por meio de testes como o PISA, e o rankeamento das escolas, utilizando-se deste critério, podem revelar modelos de accountability que induzem a retracção (real ou ideologicamente construída) dos Estados, levando a uma racionalização de custos e investimentos públicos e permitindo a indução de lógicas de coresponsabilização da sociedade civil, induzindo a expansão do mercado (e do quase-mercado) em educação. 
cujos indicadores estão relacionados com o uso dos recursos tecnológicos e a demanda cognitiva para a resolução das questões do PISA.

b) Uso dos recursos tecnológicos para a resolução das questões de Ciências do PISA

Com relação à percepção dos alunos sobre as questões de Ciências da prova do PISA, verifica-se que alguns disseram que foi uma experiência diferente e outros falaram que não gostaram. Como relatado anteriormente, pela primeira vez no Brasil, a prova do PISA em 2015 foi realizada totalmente por meio do computador. As falas a seguir revelam as percepções dos alunos:

"Eu gostei, achei diferente." (Aluno A)

"Não gostei, porque [a gente] passa a vida toda fazendo [a prova] no lápis e na folha. E no computador... achei diferente, não gostei." (Aluno B)

"Não foi difícil mexer com o computador, as questões que estavam difíceis." (Aluno D)

Os fragmentos de fala dos alunos nos mostram que a leitura de gráficos e tabelas, por meio de simulações e mudanças de variáveis propostas, implica em procedimentos psicológicos associados à compreensão e à interpretação das informações fornecidas, que nem sempre os alunos conseguem demonstrar ("porque [a gente] passa a vida toda fazendo [a prova] no lápis e na folha. E no computador...achei diferente...”).

$\mathrm{O}$ fato de os alunos reconhecerem que a prova foi diferente indica que eles não têm o costume de desenvolver atividades de Ciências por meio do computador. A dificuldade não está nas competências digitais ("Não foi difícil mexer com o computador..."), mas em como relacionar e aplicar o conteúdo científico escolar nas questões da prova ("as questões que estavam dificeis"). Para eles é fácil manusear o computador, mas é trabalhoso resolver questões de simulação e gráficos. Para exemplificar, seguem algumas respostas que confirmam nossa análise:

"Difíceis." (Aluno A)

"Porque tinham questões com gráficos que nós nem sabíamos." (Aluno B)

A partir destes fragmentos de respostas, verifica-se que os alunos apresentam dificuldades em dar soluções aos problemas apresentados. Segundo Fernandes et al. (2015), as dificuldades em desenvolver competências digitais no ensino de Ciências estão mais relacionadas ao docente do que aos alunos. Para estes autores, a dificuldade está em desenvolver metodologias didático-pedagógicas mais significativas, fazendo uso das tecnologias digitais. Essas dificuldades são mais acentuadas quando os professores não tiveram na sua formação inicial componentes de tecnologias de informação e comunicação no contexto das disciplinas de metodologia de Ciências, didática e estágio supervisionado. Hoje em dia, ainda que as escolas tenham dificuldades em ter computadores e laboratórios de informática, vários alunos possuem smartphones com acesso à internet que poderiam ser utilizados para fins de aprendizagem. A questão é: como fazer com que os alunos utilizem recursos digitais para este fim? 
c) Demanda cognitiva em relação às questões de Ciências do PISA

Ao serem questionados sobre o grau de dificuldade das questões do PISA (baixa, média e alta), alguns estudantes indicaram que as questões de Ciências tinham um grau médio de dificuldade, enquanto outros responderam que existiam questões difíceis, conforme se vê nas falas a seguir:

"Era grau de dificuldade médio." (Aluno A)

"Eu achei mais difícil a parte que tinha matemática." (Aluno C)

"Eram difíceis, porque tinham questões que nós nem sabíamos." (Aluno E)

Para uns, a dificuldade estava no raciocínio lógico matemático das questões (“... achei mais difícil a parte que tinha matemática'). Para outros, a dificuldade estava nos conteúdos conceituais ("porque tinham questões que nós nem sabíamos"). Alguns itens do PISA demandaram a execução de tarefas interativas para chegar à resposta, como a manipulação de variáveis em uma simulação.

$\mathrm{O}$ uso do computador gerou novas possibilidades de responder uma prova, entre elas a seleção de textos em uma lista para completar uma frase, o movimento de elementos gráficos na tela para preencher lacunas ou ordená-los e análise de simulações e gráficos a partir de situações-problemas. Conforme apontado anteriormente, verificou-se a partir das respostas dos alunos que o problema não estava no formato digital das questões, mas na falta de conhecimento dos conteúdos conceituais e procedimentais.

\section{Categoria 2: Percepções do discente sobre os tipos de conhecimento científico}

Nesta categoria foram evidenciadas as percepções dos alunos sobre os tipos de conhecimentos científicos desenvolvidos em sala de aula. Em busca de respostas, os alunos foram questionados sobre a abordagem dos conteúdos de Ciências, o conhecimento de procedimentos padronizados e o processo de construção do conhecimento da Ciência. Neste sentido, emergiram as seguintes subcategorias: 1. Caracterização do conhecimento dos conteúdos de Ciências; 2. Caracterização dos conhecimentos procedimentais; e 3. Caracterização dos conhecimentos epistemológicos.

a) Caracterização do conhecimento dos conteúdos de Ciências

Quando questionados sobre como eram as aulas de Ciências e se os termos científicos são abordados no cotidiano na sala de aula, os alunos relataram que:

"[O ensino de Ciências é] de baixa complexidade, baixa mesmo. O professor cobra menos." (Aluno D)

“Cobra menos.” (Aluno B)

Diante destas respostas, o que seria um ensino de Ciências de qualidade? Para nós, trata-se de um ensino em que as estratégias didáticas estariam voltadas para a aprendizagem de conceitos e fatos em contextos significativos para os alunos. Também 
trata-se de um ensino que eles enfrentem diversas situações que requeiram outras habilidades intelectuais, além da memória, como por exemplo, o desenvolvimento de procedimentos e atitudes (Coll, 2000). Conforme nos alertam Sasseron e Carvalho (2011), um ensino de Ciências de qualidade, baseado na alfabetização científica, envolve a compreensão básica de termos, conhecimentos científicos fundamentais; a compreensão da natureza da ciência e dos fatores éticos e políticos que circundam sua prática; e o entendimento das relações existentes entre ciência, tecnologia, sociedade e meio ambiente.

A partir dos fragmentos de fala dos alunos, verificou-se que um dos motivos que explicam o baixo resultado dos alunos em testes sistêmicos, como o PISA, é a qualidade do ensino de Ciências recebido por eles (" $[O$ ensino de Ciências é] de baixa complexidade... O professor cobra menos. (Aluno D)"). Entende-se que esta não é uma característica somente desta escola, mas que em muitas escolas ainda há ênfase em um ensino que privilegia a memória, sem a preocupação de levar os estudantes a desenvolver habilidades cognitivas ou até mesmo em desenvolver os eixos estruturantes da alfabetização científica de Sasseron e Carvalho (2011). Segundo Fernandes e Santos (2018), os professores o fazem não por mero acaso, mas por reproduzir a abordagem e os métodos de ensino de Ciências que vivenciaram em sua trajetória escolar.

Outro aspecto que pode contribuir para a baixa qualidade do ensino de Ciências consiste na dificuldade dos professores de Ciências em criar estratégias que valorizam o desenvolvimento do pensar científico. Muitos deles não se preocupam, ou não sabem planejar, conduzir e desenvolver atividades investigativas, habilidades de argumentação e de comunicação de ideias científicas entre seus alunos (Fernandes \& Santos, 2018). Percebe-se que ainda existem dificuldades de desenvolver tais ações na escola pesquisada.

b) Caracterização dos conhecimentos procedimentais

Os alunos também foram questionados sobre o desenvolvimento dos conhecimentos procedimentais na sala de aula, por exemplo, habilidades necessárias para as atividades investigativas e experimentais, desenvolvimento de projetos etc. A maioria respondeu que:

"Nunca participei disso não." (Aluno A)

"Não tem isso." (Aluno B)

Conforme apontam Maia e Justi (2008), o aprendizado sobre os processos de investigação em Ciências requer o desenvolvimento de habilidades como seleção e controle de variáveis, formulação de hipóteses, interpretação de padrões de evidência, observação e comunicação dos resultados, e que estão relacionadas à aprendizagem de procedimentos. A avaliação proposta pelo PISA buscou identificar diferentes conteúdos procedimentais para que os alunos pudessem responder suas questões. Para desenvolver a aprendizagem dos procedimentos é importante que os alunos sejam estimulados a refletir sobre o motivo de realizar certas ações e como realizá-las, em vez de apenas executá-las mecanicamente, ou seja, para que sejam efetivamente aprendidas, as ações 
devem estar relacionadas a algum problema conceitual e significativo que se pretende resolver.

Verificou-se, a partir dos fragmentos de fala dos alunos, que os conteúdos procedimentais parecem não ter sido bem desenvolvidos nas aulas de Ciências ("Nunca participei disso não (Aluno A)"). Segundo a percepção do professor sobre os conteúdos procedimentais, para que o aluno consiga compreender um conceito é preciso desenvolver certos procedimentos (investigativos, resolução de problemas etc.) para alcançar a aprendizagem de Ciências e compreensão dos conceitos científicos (Sasseron, \& Carvalho, 2011; Gonçalves, \& Marques, 2006; Fernandes et al. 2015).

c) Caracterização dos conhecimentos epistemológicos

Quando foi perguntado aos estudantes se existiam momentos de diálogos durante o processo de ensino-aprendizagem, nos quais eles poderiam estruturar seu conhecimento através do exercício do pensamento, propondo hipóteses, refletindo, observando e indagando sobre teorias e observações e desenvolvendo seu pensamento crítico, as respostas foram do tipo:

"Nós nem temos laboratório." (Aluno B)

"É sempre a mesma coisa." (Aluno F)

Verifica-se que os alunos demonstram dificuldade em estruturar o seu conhecimento através de reflexões, observações, indagações. Para eles, o ensino de Ciências que recebem "É sempre a mesma coisa".

Para os alunos, esse tipo de conhecimento só é possível se existir um "laboratório" para que eles possam refletir e analisar situações para construir conhecimento, uma vez que suas aulas não mudam, são "sempre a mesma coisa". Para nós, o conhecimento epistemológico é mais do que apontado pelos estudantes, refere-se a construtos e características essenciais para o processo de construção do conhecimento científico, por exemplo, o levantamento de uma hipótese, a explicação de uma teoria ou de uma observação baseada em fatos históricos etc. (Fernandes et al. 2018).

\section{Categoria 3. Percepções sobre o letramento científico/ alfabetização científica do discente}

Esta última categoria buscou identificar se o aluno possui certas habilidades como explicar fenômenos científicos e tirar conclusões baseadas em evidências científicas sobre questões relacionadas à Ciências. Assim, a fim de compreender o letramento científico ou a alfabetização científica dos participantes, foi evidenciada somente a seguinte subcategoria:

Caracterização das competências requeridas para o letramento científico ou alfabetização científica do aluno

Os alunos foram questionados se o ensino de Ciências que recebem permite: i) a compreensão básica de termos e conhecimentos científicos fundamentais; ii) a compreensão da natureza da ciência e dos fatores éticos e políticos que circundam sua 
prática; e iii) o entendimento das relações existentes entre ciência, tecnologia, sociedade e meio ambiente (conforme Sasseron \& Carvalho, 2011 ou a Visão II de Roberts, 2007). Verificou-se que não foi possível determinar os eixos estruturantes da alfabetização científica de Sasseron e Carvalho (2011), uma vez que não existe um ensino que associe os conteúdos científicos com o dia a dia dos alunos. Alguns fragmentos de fala exemplificam esta constatação:

Pesquisador: "Então, o professor traz uma situação problema para aplicar conceitos científicos, discute com vocês temas relacionados com sexualidade, droga aqui na escola e os problemas ambientais da cidade?"

Aluno A: "Não temos isso aqui. Os professores passam matéria no quadro e manda a gente copiar. Tem professor que não corrige as atividades e tem vez que nem explica direito."

Aluno D: "Aula sem quadro, fora da sala, é mais fácil de entender."

Um dos principais objetivos da educação científica é favorecer o processo de alfabetização científica dos alunos, considerando aqui não apenas a importância dos conceitos e teorias, conhecimento das práticas em que se baseia a investigação empírica, como a repetição de medidas, o controle de variáveis e as estratégias utilizadas em todas as formas de investigação científica, mas também valorizar o conhecimento epistemológico, que consiste no entendimento da função de perguntas, observações, teorias, hipóteses, modelos e argumentos na ciência (Sasseron \& Carvalho, 2011).

As questões do PISA também buscaram verificar o "letramento científico" dos alunos por meio de competências, tipos de conhecimento científico, contextos e demanda cognitiva (conforme Inep, 2016b ou a Visão I de Roberts, 2007), porém, os mesmos demonstram dificuldades, conforme evidenciado pelas falas abaixo:

Pesquisador: "Se um professor pede a vocês que realizem um procedimento de uma única etapa, por exemplo, recordação de um fato, termo, princípio, conceito ou localizar uma única informação no gráfico ou tabela, pegar os conceitos e tentar aplicar os conceitos nesse tipo de gráfico... vocês conseguiriam associar conceitos em um gráfico?”

Alunos: "Não conseguiríamos."

Não foi possível identificar, nas falas dos alunos, os elementos que caracterizam a alfabetização científica (Sasseron \& Carvalho, 2011) e o letramento científico (Inep, 2016b), indicando que o objetivo do PISA em avaliar "contextos, conhecimento, competências e atitudes" (Inep, 2015b) para o ensino de Ciências não foi atingido para este caso analisado.

Neste sentido, considera-se que o ensino de Ciências deve ser pensado de forma mais ampla, contemplando não somente conhecimentos conceituais e procedimentos. O ensino de Ciências, assumido como meio para se alcançar a alfabetização científica, implica em práticas pedagógicas que envolvem e desenvolvem a atividade intelectual, o pensar crítico e autônomo, a mobilização consciente e intencional de recursos cognitivos 
e metacognitivos. Para construir estas práticas, se faz necessário uma formação (inicial e continuada) mais qualificada e articulada com a pesquisa teórica e aplicada da educação científica. Por exemplo, o professor precisaria entender mais sobre: as relações de similaridades entre os processos de leitura e escrita de signos e significados de questões científicas; a elaboração e condução de atividades de investigação científica; como se ensina a identificar uma evidência como tal; como ensinar a observar, descrever, interpretar, explicar, além de construir instrumentos para avaliar a alfabetização científica.

\section{Considerações finais e perspectivas}

O letramento científico do PISA 2015 tem como indicadores um conjunto de categorias (os tipos de conhecimento científico, contextos e demanda cognitiva) e três competências científicas que buscam identificar se os alunos conseguem: 1) Explicar fenômenos cientificamente; 2) Avaliar e planejar experimentos científicos; e 3) Interpretar dados e evidências cientificamente (Inep, 2016a). Com base nessas categorias, a pesquisa buscou compreender a qualidade do ensino de Ciências numa escola pública no Vale do Jequitinhonha (MG) e como os seus alunos compreendem a prova de Ciências do PISA 2015. Os resultados, a partir do contexto geral das respostas do professor de Ciências e alunos participantes do PISA de 2015, demonstraram que o "letramento científico" ainda é muito pouco atingido no ensino de Ciências. Embora o professor afirme tentar promover os indicadores de alfabetização científica de Sasseron e Carvalho (2008) ou as categorias do letramento científico do PISA de 2015 com os alunos, suas limitações e as da escola são possíveis barreiras para a qualidade do ensino de Ciências que, por sua vez, poderia influenciar nos resultados do PISA. Diferentes estratégias de ensino, entre elas, o desenvolvimento de atividades investigativas seria uma possibilidade para alcançar as categorias do PISA, uma vez que este tipo de atividade pode fazer com que os alunos sejam capazes de explicar diferentes fenômenos científicos e interpretar os dados relacionando-os com o seu cotidiano. Também foi identificado que não se pode afirmar que o ensino de Ciências da escola participante tenha a preocupação de desenvolver em seus alunos a competência de aplicar o conteúdo científico escolar em contextos do dia a dia. Essa observação fomenta reflexões sobre a qualidade do ensino e da formação de professores de Ciências numa perspectiva de alfabetização científica.

Foi possível verificar, a partir da análise dos dados, que o PISA tende a ter um caráter neotecnicista de letramento científico, gerando desconfiança nas escolas nas quais é aplicado e pode estar medindo "tipos de conhecimento científico" diferentes em comparação com os países desenvolvidos da OCDE, uma vez que os estudantes na faixa etária de 15 anos podem estar em anos escolares diferentes, caracterizando resultados distorcidos para o Brasil.

Também foi evidenciado que os alunos não demonstraram motivação em fazer a avaliação do PISA, somente curiosidade por ser internacional e realizada pelo computador. Eles estão desestimulados em relação à escola e em realizar as avaliações 
sistêmicas e escolares, executando assim, um ritual já pré-estabelecido de recebimento e devolução de uma prova, caracterizando, mesmo que de forma inconsciente, uma banalização do sistema de avaliação.

Observamos também que a dificuldade dos alunos não está nas competências digitais, mas sim em como relacionar e aplicar o conteúdo científico escolar nas questões da prova, bem como em relacionar elementos do dia a dia com o ensino de Ciências que eles têm recebido na sala de aula. Desta forma, o problema não estava no formato diferente da prova, mediada pelo computador, mas em o aluno não conseguir resolver as questões pela falta de conhecimento dos conteúdos conceituais. Assim, segundo os alunos, um dos motivos do resultado negativo do PISA 2015 é a qualidade do ensino de Ciências que recebem. Por outro lado, na perspectiva do professor, a dificuldade está em realizar, de qualquer maneira e sem significado para os alunos, todas as avaliações sistêmicas.

Este trabalho traz, portanto, um alerta sobre o sentido e o significado da avaliação para os estudantes, seja ela sistêmica ou escolar. Os sujeitos investigados não compreendem o real objetivo de serem avaliados, o que constitui um fator extremamente preocupante para a educação em geral, e para o ensino de Ciências em particular.

Por meio da análise dos resultados desta pesquisa, verificou-se a importância de se discutir os objetivos do ensino de Ciências e o processo da alfabetização científica durante a formação dos estudantes e professores. A principal contribuição desta pesquisa para o ensino de Ciências está na atenção ao papel das avaliações sistêmicas como instrumento do desempenho dos estudantes em Ciências. Outra contribuição está na atenção que se deve dar à construção de competências de alfabetização científica pelos estudantes e professores por meio de formação inicial e continuada.

Por fim, este trabalho corrobora muitas lacunas identificadas na literatura sobre esta temática, principalmente relacionadas à compreensão das avaliações sistêmicas por professores e estudantes e à inserção e compreensão da alfabetização científica no ensino de Ciências e na formação permanente dos professores. Pinto et al. (2016) também ressaltam essas lacunas em estudos sobre o PISA e o ensino de Ciências. Por isto, entende-se que existe uma necessidade de maior investimento em investigações na área, aproveitando o manancial de dados gerados pelo PISA.

\section{Agradecimentos}

Ao professor e estudantes participantes e à Fundação de Amparo à Pesquisa do Estado de Minas Gerais que financiou esta pesquisa.

\section{Referências}

Afonso, A. J. (2009). Nem tudo o que conta em educação é mensurável ou comparável: Crítica à accountability baseada em testes estandardizados e rankings escolares. Revista Lusófona de Educação, 13, 13-29. 
André, M. (2011). Pesquisa sobre formação de professores: tensões e perspectivas do campo. Coleção ANPED Sudeste 2011 (pp. 24-36). Rio de Janeiro, RJ: livro 2. Recuperado de http://www.fe.ufrj.br/anpedinha2011/ebook2.pdf.

MEC (2014). Lei 13.005, de 25 de junho de 2014. Aprova o Plano Nacional de Educação - PNE e dá outras providências. Recuperado de http://presrepublica.jusbrasil.com.br/ legislacao/125099097/lei-13005-14.

Carvalho, L. M. (2009). Governando a Educação pelo Espelho do Perito: Uma Análise do PISA como Instrumento de Regulação. Educação \& Sociedade, Campinas, 30(109), 1009-1036. https://dx.doi.org/10.1590/S0101-73302009000400005.

Coll, C. (2000). As contribuições da psicologia para a educação: teoria genética e aprendizagem escolar. In. L. Banks-Leite. (Org.), Piaget e a Escola de Genebra (pp. 164197). São Paulo, SP: Cortez.

Delizoicov, D., Angotti, J. A., \& Pernambuco, M. M. C. A. (2011) Ensino de ciências: fundamentos e métodos. 3. ed. São Paulo: Cortez, 364 p.

Fernandes, G. W. R., \& Santos, D. L. (2018). O ensino de Ciências na atualidade: alguns obstáculos e outros enfoques. In Tamanine, P. A. (Org.). O ensino em perspectivas: múltiplas abordagens, outros enfoques e a interdisciplinaridade no ofício docente (pp. 51-63). Curitiba: Editora CRV.

Fernandes, G. W. R., Rodrigues, A. M., \& Ferreira, C. A. (2018). Elaboração e validação de um instrumento de análise sobre o papel do cientista e a natureza da ciência e da tecnologia. Investigações em Ensino de Ciências, 23(2), 256-290. https://doi. org/10.22600/1518-8795.ienci2018v23n2p256.

Fernandes, G. W. R., Rodrigues, A. M., \& Ferreira, C. (2015). Módulos temáticos virtuais: uma proposta pedagógica para o ensino de ciências e o uso das TICs. Caderno Brasileiro de Ensino de Física, 32(3), 934-962. https://doi.org/10.5007/2175-7941.2015v32n3p934.

Gatti, B. A. (2009). Licenciatura: Crises Sem Mudanças? In A. I. L. F. Dalben, J. Diniz, L.Leal, \& L.Santos. Convergências e tensões no campo da formação e do trabalho docente. (pp. 485-509). Belo Horizonte: Autêntica.

Gonçalves, F. P., \& Marques, C. A. (2006). Contribuições pedagógicas e epistemológicas em textos de experimentação no ensino de química. Investigações em Ensino de Ciências, 11 (2), 219-238.

Gui, R. (2003). Grupo focal em pesquisa qualitativa aplicada: intersubjetividade e construção de sentido. Revista Psicologia: Organizações e Trabalho, 3(1), 135-159.

Hazen, R. M., \& TrefiL, J. (1995). Saber ciência. São Paulo: Cultura Editores Associados.

Inep. (2010). OECD, PISA 2009. Results: What Students Know and Can Do Student Performance in Reading, Mathematics and Science (Volume I), http://dx.doi. org/10.1787/9789264091450-en. 
Inep. (2011).PISA. Brasília, 2011. Recuperadodehttp://portal.inep.gov.br/pisaprogramainternacional-de-avaliacao-de-alunos.

Inep. (2013). OECD, PISA 2012. Résultats du PISA 2012: Savoirs et savoir-faire des élèves (Volume I): Version préliminaire - Performance des élèves en mathématiques, en compréhension de l'écrit et en sciences, 2013. Recuperado de http://www.oecd-ilibrary. $\mathrm{org} /$ education/resultats-du-pisa-2012-savoirs-et-savoir-faire-des-eleves-volumei_9789264204508-fr.

Inep. (2015a). Análises e reflexões sobre o desempenho dos estudantes brasileiro. Recuperadodehttp://download.inep.gov.br/acoes_internacionais/pisa/resultados/2015/ pisa2015_completo_final_baixa.pdf.

Inep. (2015b). OECD PISA 2015 - Programa Internacional de Avaliação de Estudantes. Matriz de Avaliação de Ciências. Relatório 2015. Recuperado de http://download. inep.gov.br/acoes_internacionais/pisa/marcos_referenciais/2015/matriz_de_ciencias_ PISA_2015.pdf

Inep. (2016a). Brasil no PISA 2015: sumário executivo. Relatório INEP 2016. Recuperado de http://download.inep.gov.br/acoes_internacionais/pisa/documentos/2016/pisa_ brasil_2015_sumario_executivo.pdf.

Inep. (2016b). OECD, PISA 2015 - Programa Internacional de Avaliação de Estudantes. Exemplos de Itens liberados de Ciências, 2016. Recuperado de http://download.inep. gov.br/acoes_internacionais/pisa/itens/2015/itens_liberados_ciencias_pisa_2015.pdf

Inep. (2016c). Programa Internacional de Avaliação de Estudantes - PISA 2015 OECD, 2016b. Recuperado de http://portal.inep.gov.br/pisa-programa-internacional-deavaliacao-de-alunos.

José, W., Angotti, J., \& Bastos, F. (2016). Ensino de Física por meio de questões do PISA associadas a Temas Estruturadores e Conceitos Unificadores. Caderno Brasileiro de Ensino de Física, 33(2), 333-354. https://doi.org/10.5007/2175-7941.2016v33n2p333

Lebrun. (2008). Teorias e Métodos Pedagógicos para Ensinar e Aprender. Lisboa: Instituto Piaget.

Lüdke, M., \& André, M. E. D. A. (1986). Pesquisa em educação: abordagens qualitativas. São Paulo: EPU.

Maia, P. F., \& Justi, R. (2008). Desenvolvimento de habilidades no ensino de ciências e o processo de avaliação: análise da coerência. Ciência \& Educação, Bauru, 14(3), 431-450. http://dx.doi.org/10.1590/S1516-73132008000300005.

Moraes, R., \& Galiazzi, M. C. (2011). Análise Textual Discursiva. Ijuí: UNIJUí.

Moraes, R. (2003). Uma tempestade de luz: a compreensão possibilitada pela análise textual discursiva. Ciência \& Educação, 9(2), 191-211. http://dx.doi.org/10.1590/S151673132003000200004 . 
Nora, P. Dos S., \& Broietti, F. C. D. (2017). Um estudo das questões de ciências do PISA: analisando os conceitos transversais. ACTIO: Docência em Ciências, 2(3), 60-78. https:// doi.org/10.3895/actio.v2n3.6991.

Nora, P. Dos S., Broietti, F. C. D., \& Passos, M. M. (2016). Análise das Práticas Científicas em questões que envolvem conceitos químicos do PISA. Anais do XVIII Encontro Nacional de Ensino de Química (XVIII ENEQ). Florianópolis, SC. Recuperado de http:// www.eneq2016.ufsc.br/anais/resumos/R1558-1.pdf.

Pinto, J. S., Silva, J. C., \& Bixirão Neto, T. (2016). Fatores influenciadores dos resultados de matemática de estudantes portugueses e brasileiros no PISA: revisão integrativa. Ciência \& Educação , 22(4), 837-853. https://dx.doi.org/10.1590/1516-731320160040002

Rodrigues A. P. de N., \& Cruz, L. G. (2017). Por que vamos mal em Ciências?"- O que dizem os professores do munícipio de Ivinhema (MS) sobre os resultados do Programa Internacional de Avaliação de Estudantes (Pisa). Atas do XI Encontro Nacional de Pesquisa em Educação em Ciências - XI ENPEC. Florianópolis-SC. Recuperado de http://www. abrapecnet.org.br/enpec/xi-enpec/anais/resumos/R1876-1.pdf.

Roberts, D. A. (2007). Scientifc literacy/science literacy. In: Abell, S. K.; Lederman, N. G. (Ed.). (2007). Handbook of research on science education (pp. 729-782). Londres: Lawrence Erbaum Associates.

Saldanha, P. (2018). Alunos brasileiros não chegam ao fim de prova em avaliação mundial. [Artigo]. Educação. Recuperado de https://www1.folha.uol.com.br/educacao/2018/07/ alunos-brasileiros-nao-chegam-ao-fim-de-prova-em-avaliacao-mundial.shtml.

Sasseron, L. H., \& Carvalho, A. M. P. (2008). Almejando a alfabetização científica no ensino fundamental: a proposição e a procura de indicadores do processo. Investigações em Ensino de Ciências, 13(3), 333-352.

Sasseron, L. H., \& Carvalho, A. M. P. (2011). Alfabetização Científica: uma revisão bibliográfica. Investigações em Ensino de Ciências. 16(1), 59-77.

Sjøberg. S. (2017). PISA as a challenge for science education: inherent problems and problematic results from a global assessment regime. Revista Brasileira de Pesquisa em Educação em Ciências. 17(1), 327-363. https://doi.org/10.28976/19842686rbpec2017171327

Sousa, A. B. (2009). Investigação em Educação (2nd ed.). Lisboa: Livros Horizonte.

Vieira, A. M. (2017). Acordes e dissonâncias do letramento científico proposto pelo PISA 2015. Estudos em Avaliação Educacional. 28(68), 478-510. http://dx.doi.org/10.18222/ eae.v28i68.4410 
Wittmann, M. J. M. (2008). Avaliação da educação básica em larga escala em nível nacional: previstos e acontecidos. In $8^{\circ}$ Congresso Nacional de Educação da PUCPR (EDUCERE). Anais do $8^{\circ}$ EDUCERE. Curitiba: Pontifícia Universidade Católica do Paraná. Recuperado de http://www.pucpr.br/eventos/educere/educere2008/anais/ pdf/92_60.pdf.

Adriana Aparecida Ranulfo

${ }^{(0)}$ https://orcid.org/0000-0002-7154-7797 Universidade Federal dos Vales do Jequitinhonha e Mucuri Departamento de Ciências Biológicas (DCBio) Diamantina, Minas Gerais, Brasil sorelaranulfo@hotmail.com

\section{Geraldo W. Rocha Fernandes}

http://orcid.org/0000-0002-1337-1236 Universidade Federal dos Vales do Jequitinhonha e Mucuri Departamento de Ciências Biológicas (DCBio) Diamantina, Minas Gerais, Brasil geraldo.fernandes@ufvjm.edu.br

Luciana Resende Allain

http://orcid.org/0000-0002-7050-1164 Universidade Federal dos Vales do Jequitinhonha e Mucuri Departamento de Ciências Biológicas (DCBio) Diamantina, Minas Gerais, Brasil luciana.allain@gmail.com

Submetido em 22 de Setembro de 2018 Aceito em 25 de Março de 2019 Publicado em 14 de Junho de 2019 